\title{
Gill-cleaning mechanisms of the crayfish Procambarus clarkii (Astacidea: Cambaridae): experimental testing of setobranch function
}

\author{
Raymond T. Bauer \\ Department of Biology, University of Southwestern Louisiana, Lafayette, LA, 70504-2451, USA
}

\begin{abstract}
Gills of the crayfish Procambarus clarkii are cleaned by two sets of setae which are thrust back and forth among gill filaments by feeding, locomotory, or other movements of thoracic legs. Setae with a complex, rasping microstructure arise from papillae (setobranchs) on the third maxillipeds and pereopods 1-4, and extend up between the inner layer of arthrobranch and outer layer of podobranch gills. The lateral sides of the podobranchs, beyond the range of the setobranch setae, are penetrated by a field of setae projecting from the inner side of the gill cover. These branchiostegal setae bear digitate scale setules like those borne by the setobranch setae. Although cleaning setae act concomitantly with any type of leg movement, these animals engage in a previously unreported behavior, "limb rocking," whose sole function appears to be gill cleaning.

The effectiveness of cleaning setae was tested with experiments in which setobranch setae were removed from the branchial chamber of one side but not the other. Treated crayfishes set out in commercial ponds and a natural swamp habitat suffered heavy particulate fouling on gill filaments deprived of setobranch setae. The pattern of fouling showed that branchiostegal setae also prevented particulate fouling. However, gill-cleaning setae were not effective against bacterial or ciliate fouling. It is concluded that molting is the only escape from epibiotic fouling in P. clarkii.

It is suggested that setobranchs of other decapods, e.g., some families and genera of caridean shrimps, are also adaptations preventing particulate but not epibiotic fouling. Thus, indirect gill-cleaning mechanisms, such as setobranchs, are less effective than gill brushing by chelipeds (found in many species of Caridea and Anomura), which has been shown experimentally to prevent all gill fouling. This supports the view that gill brushing is more advanced than setobranch or other indirect gill-cleaning methods, both in the functional and evolutionary sense.
\end{abstract}

Additional key words: crayfish, epibiont, fouling, grooming, setae

The gills of decapod crustaceans, enclosed in a branchial chamber, are subject to deleterious fouling by particulate debris and epibiotic growth (Bauer 1981, 1989). A variety of mechanisms for prevention and removal of gill fouling have evolved in the Decapoda. In some taxa, there is an active (direct) gillcleaning mechanism, cheliped brushing. Chelipeds with small chelae bearing tufts of setae are inserted into the branchial chamber, vigorously brushing, scraping, and picking among the gill filaments. Cheliped brushing has been reported and described in several families of caridean shrimps, in stenopodidean shrimps, and in anomurans such as the porcellanid, galatheid, and lithodid crabs (Bauer 1989; Pohle 1989). The high efficiency of cheliped brushing in pre- venting a heavy buildup of particulate and epibiotic fouling on gills has been demonstrated experimentally in a caridean shrimp (Bauer 1979) and a lithodid crab (Pohle 1989).

Other decapods use what may be termed a passive (indirect) method for gill cleaning. Structurally complex setae, arising directly from papillae (setobranchs) or epipods borne on various thoracic appendages, are located among the gills. When the limb is moved during locomotion, feeding, or other activities, the complex setae on the coxal epipod or setobranch are jostled among the gill filaments. Examples of passive gillcleaning structures are setiferous epipods in penaeoid shrimps, palinurid lobsters, nephropid lobsters, and brachyuran crabs, as well as setobranchs in some families of Caridea, in axiid thalassinoids, and in parastacoid and astacoid crayfishes (Bauer 1989). Presum- 
ably, the action of these setiferous processes prevents or removes fouling material, as suggested by Huxley (1880) for setobranch setae in crayfishes. However, there have been no experimental studies showing the effectiveness of these structures as a gill-cleaning mechanism.

The objective of this study was to determine the possible role of setobranch setae in gill cleaning in the red swamp crawfish, Procambarus clarkii (GIRARD 1852). Observations on gross structure, scanning electron microscopy (SEM) on setal microstructure, and experimental exposure of these crayfishes to fouling in commercial ponds and natural habitats were used to test hypotheses on the action and efficacy of setobranchs. In addition, the functional morphology of branchiostegal (gill cover) setae, previously unreported in connection with gill cleaning, was investigated. The results are discussed in light of the evolution of gillcleaning mechanisms in the Decapoda.

\section{Methods}

Live crayfishes were obtained from commercial ponds in Breaux Bridge, Louisiana. Specimens maintained alive were kept in water tables or in a large (3.7 $\mathrm{m}$ diameter) ring tank with recirculation of water through fiber and subgravel filters, respectively. Feeding was ad libitum with shrimp pellets or large pellets of commercial crayfish bait. Specimens used for observations on gross morphology or scanning electron microscopy (SEM) were initially preserved in 10\% buffered formalin. Species identification of Procambarus clarkii was made using the criteria of Penn (1959) and Hobbs (1974). Preparation of body parts for SEM consisted of washes in distilled water, a graduated series of ethyl alcohol from 12-100\%, drying with $\mathrm{CO}_{2}$ in an EMS 850 critical point dryer, and sputter-coating with gold-palladium for $2-8$ minutes ( $10-$ $20 \mathrm{~nm} / \mathrm{min}$ ), with the longer coating times for larger, topographically more complex specimens. Specimens were viewed with a JEOL $7000 \mathrm{FV}$ scanning electron microscope at an accelerating voltage of $15 \mathrm{kv}$.

A behavior considered relevant to gill cleaning, "limb rocking," is described and data on its frequency and duration are reported; a full description of grooming behaviors of $P$. clarkii will be reported elsewhere (unpubl. data). Time lapse video observations of crayfish grooming behaviors, including possible gill-cleaning behavior, were done on 24 crayfishes. Each crayfish was placed in a partitioned aquarium in a space $17 \mathrm{~cm} \times 25 \mathrm{~cm}$ with $20 \mathrm{~cm}$ water depth. Each was observed for a 24-h period with a light:dark cycle varying from 10 to $14 \mathrm{~h}$ light (overhead fluorescent lighting). Night observations were conducted with in- frared lamps $(880 \mathrm{~nm})$. Water temperature varied from 15 to $20^{\circ} \mathrm{C}$. Observations were recorded with a lowlight, infrared-sensitive surveillance video camera with an $8 \mathrm{~mm}$ or $12.5 \mathrm{~mm}$ lens connected to a time lapse video recorder system, with recordings made during a period of $24 \mathrm{~h}$ at a speed of 5 pictures/s. Data were collected on the number occurrences/h and total time spent (duration $/ \mathrm{h}$ ) in several categories of cleaning behaviors, including limb rocking.

Experiments on effectiveness of setobranchs in gill cleaning consisted of partial ablation of crayfish setobranchs with subsequent exposure to natural fouling. Setobranchs were removed from one gill chamber ("experimental chamber") but not the other ("control") in individual ("treated") crayfishes. Living animals were held under a stereomicroscope, and watchmaker's forceps were used to reach under the gill cover (branchiostegite) to grasp and remove the setobranch setae from pereopods 1-4. Removal of those of maxilliped 3 was not attempted because of difficulty in grasping these setae without damage to the animal. From one to several days before setobranch removal, the fingers of the major chelae (first pereopods) were glued shut using cyanoacrylate glue. This prevented damage to the author during ablations and among crayfishes when maintained together in cages during the experiment. Additionally, a small $\left(\sim 5-8 \mathrm{~mm}^{2}\right)$ piece of labeling tape was affixed dorsally on the carapace with cyanoacrylate glue in order to easily detect unmolted, treated animals in holding tanks.

Experimental exposure of treated crayfishes to ambient fouling took place in a "pond" and a "swamp" habitat. Treated crayfishes were place in cylindrical cages ("eel-pots" or traps, $80 \mathrm{~cm}$ long, $22 \mathrm{~cm}$ diameter, $5 \mathrm{~mm}$ mesh, with trap entrances closed) at a density of 30-40 per cage. In the "pond" experiment, treated crayfishes were placed on the bottom in a commercial crayfish pond near Breaux Bridge, Louisiana $\left(30^{\circ} 15^{\prime} \mathrm{N}, 91^{\circ} 50^{\prime} \mathrm{W}\right)$; the average depth of the pond was $\sim 0.6-1.0 \mathrm{~m}$. Setobranch ablation took place on 5-6 Dec. 1995; cages were set in the pond on 7 Dec. and removed on 20 Dec. (exposure of 13 days). The "swamp" experiment took place in Little Sorrel Bayou $\left(29^{\circ} 48^{\prime} \mathrm{N}, 91^{\circ} 16^{\prime} \mathrm{W}\right)$, located in the Atchafalaya swamp (Floodway), a natural habitat of $P$. clarkii, with cages on the bottom at an initial depth of $\sim 1.5 \mathrm{~m}$. The ablations for this experiment were done on 10-11 Jan. 1997, and cages were set out on 23 Jan. The cages with crayfishes used in this experiment could not be recovered until 3 March because of increased water levels, with a total exposure time in the swamp of 48 days.

When cages were removed from habitats, crayfishes were preserved in buffered formalin. Post-hoc inspec- 
tion of ablated crayfishes showed that the removal of setobranch setae was most complete from the setobranchs of pereopods 2-4. The gills of either pereopod 2 or 3 (whichever had complete ablation of the setobranch setae of that limb and the one just posterior in the "experimental" gill chamber) were chosen for analysis from 20 individuals each from the pond and swamp experiments. Gills were mounted in a standand position in a depression slide, covered with water and a cover slip, for microscopic examination with transmitted light. Particulate fouling was quantified by comparing the relative transparency of the gills of the same appendage from the "control" and "experimental" branchial chambers. Transparency was measured with a light meter whose sensor was mounted on the phototube of a compound microscope. Two standardized locations on each gill, midway between the middle and distal ("upper") end, and midway between the middle and proximal ("lower") end, were viewed at $100 \mathrm{x}$ so that the gill tissue filled the field of view. Relative transparency was defined as the reading of light intensity with the gill in the field of view divided by the intensity without the gill in view. The settings of factors that control light intensity coming up into the slide (rheostat, apertures of field and iris diaphragms, and condenser) were standardized. The light meter was set at a range of 0-200 lux (accuracy of $=$ $4 \%$ ).

Epibiotic fouling was measured with counts of a large, common, peritrichous ciliate, Cothurnia variabilis KellicotT. Counts were made on gill filaments on the medial side of experimental and control anterior arthrobranchs used for measures of particulate fouling. This gill type and section of gill were chosen because the size and arrangement of filaments were conducive for viewing and counting the ciliates.

\section{Results}

\section{Gills and setobranch setae}

Setobranch setae are located between the outer (lateral) layer of podobranchs and the inner (medial) layer of anterior and posterior arthrobranchs. Removal of the branchiostegite (gill cover) of Procambarus clarkii exposes the outer layer of epipodial gills, the podobranchs, arising from the coxae of maxillipeds $2-3$ and pereopods 1-4 (Figs. 1A, 2A). Setobranchs are small bulbous spurs or papillae on the anterior side of the coxae of the third maxillipeds and pereopods 1-4 (major chelipeds, walking legs 1-3), exposed when the podobranchs are removed (Figs. 1B, 2B-D). Arthrobranchs compose the inner layer of gills, with a posterior and anterior arthrobranch on the third maxilli- peds and pereopods 1-4 (Figs. 1B, 2B). Maxilliped 2 bears a single arthrobranch.

Setae from the setobranchs (SB) extend up as bundles between the gills of adjacent appendages (Figs. $1 \mathrm{C}, 2 \mathrm{~B}, \mathrm{C})$. One group of SB-setae of an appendage " $\mathrm{x}$ " (e.g., pereopod 2) is directed up and back towards the anterior arthrobranch and the anterior side of the medial epipodial blade of the podobranch of the same appendage (Figs. 1C, 2C; see Fig. 3 for podobranch structure). Another group of SB-setae is disposed anteriorly to contact the posterior arthrobranch of the next appendage anterior (" $\mathrm{x}-1$," e.g., pereopod 1). In addition, some of the latter group of setae extend up into the posterior sides of the epipodial blades (Fig. $3 \mathrm{~B}$ ) of the podobranch of " $\mathrm{x}-1$." The distal part of the anterior arthrobranch of " $x$ " fits against the medial epipodial blade of the podobranch of " $x-1$." Thus, the anteriorly directed SB-setae of appendage " $x$ " also touch and intertwine with gill filaments of its own anterior arthrobranch in this location as well. However, there is considerable overlap of SB-setae from adjacent appendages, especially in the dorsal part of the branchial chamber (Fig. 1C).

SB-setae do not reach the outer (lateral) side of the podobranchs, where the greatest mass of podobranch filaments are located (Figs. 1A, 2A, 3), except to emerge from among the filaments distally in the anterior part of the branchial chamber (Fig. 1A). Unlike the arthrobranchs, which consist of a central axis surrounded by filaments (Figs. 5A,B, 6A,B), the basic structure of podobranchs is a double-bladed epipod (Fig. 3). The thin medial and lateral blades of the epipod join at the gill axis in the form of a "V," convex anteriorly, deeply concave posteriorly. Most of the gill filaments are on the lateral side of the lateral blade, with some on the blade's posterior side as well (Fig. 3). The medial epipodial blade of the podobranch bears a small number of filaments anteriorly and none posteriorly (Fig. 3).

SB-setae do not simply lie between gills but instead intertwine around and among the gill filaments (Fig. $2 \mathrm{E}, \mathrm{F})$. The setae originate in deep sockets with thin cuticle (Fig. 2D) and thus are able to move flexibly. They are naked for a short distance proximally, but for most of their distance are equipped with digitate scale setules (Figs, 2E,F, 4A). Movements of limbs with setobranchs which include motion of the coxae, especially anterior-posterior motion, cause jostling of SB-setae among the gill filaments. Motion of limb coxae includes the gills, especially the podobranchs, in the branchial chamber. Gill motion causes slight pulling, pushing, and agitation of setobranch setae among and against gill filaments (Fig. 2F) and epipod surfaces. 


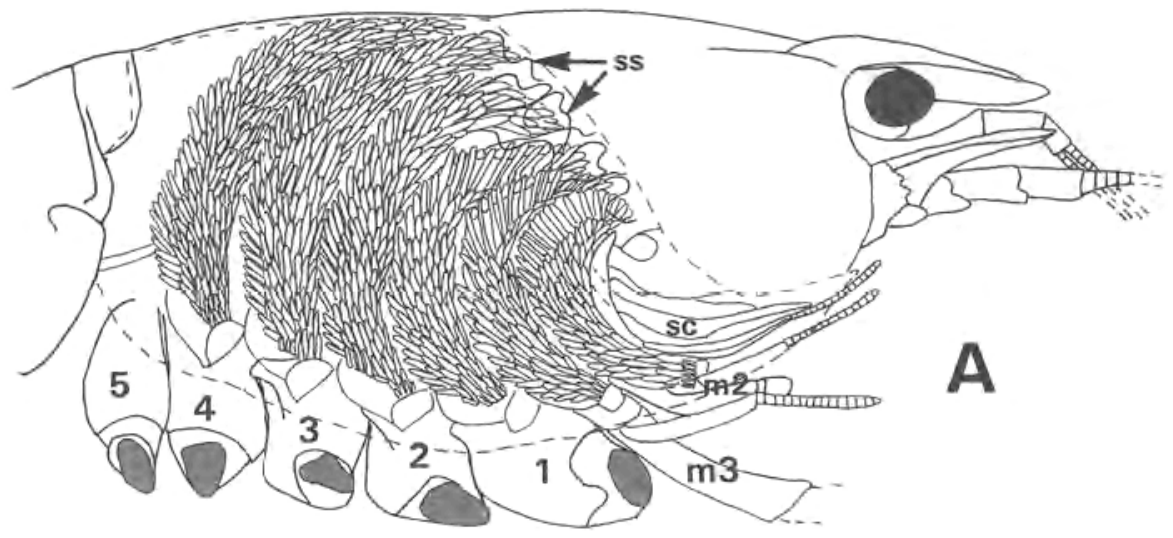

Fig. 1. Arrangement of gills and setobranchs in the branchial chamber of Procambarus clarkii. Scale bar, 1 $\mathrm{cm}$. A. View of outer layer of gills (podobranchs) when branchiostegite (gill cover) is removed (dotted line); some setobranch setae (ss) can be seen protruding from among podobranch filaments in upper right corner of branchial chamber. 1-5, pereopods $1-5 ; \mathrm{m} 2-3$, maxillipeds $2-3$; sc, scaphognathite (gill bailer); heavy shading, site of detachment (basi-ischial joint) of pereopods. B. Podobranchs removed to reveal inner layer of gills (arthrobranchs) and the setobranch papillae (arrows); third maxilliped and pereopods 1-4 each have an anterior (A) and posterior $(\mathrm{P})$ arthrobranch; second maxilliped has a single arthrobranch; lighter shading indicates sites of attachment of removed podobranchs. C. Diagrammatic representation of extent and relative abundance of setobranch setae (irregular lines arising from setobranchs) within the branchial chamber, lateral to arthrobranchs (drawn in outline).
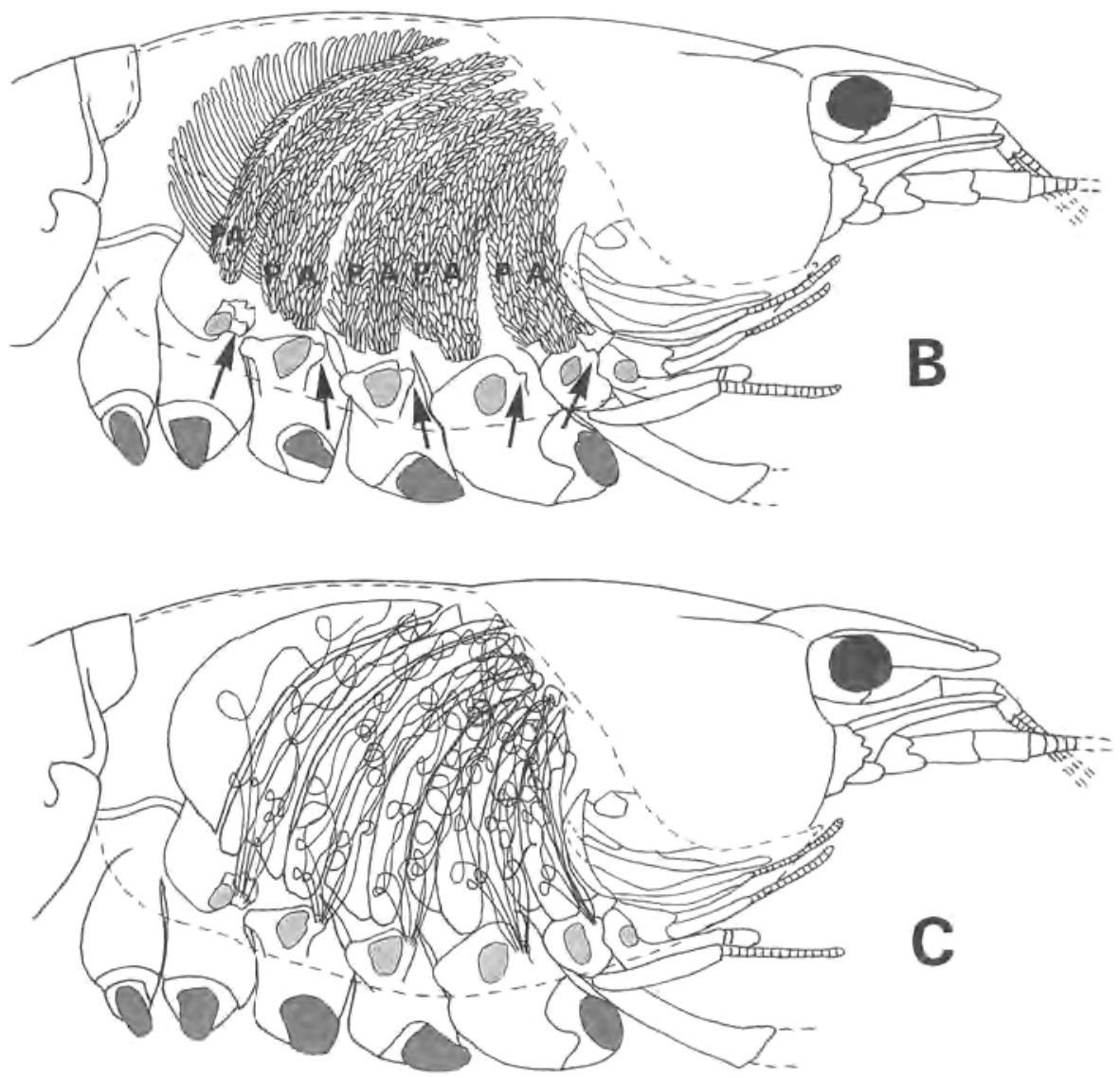

Time-lapse videos of crayfish grooming behaviors revealed a previously unreported behavior which appears to be a gill-cleaning behavior involving the setobranchs. In this behavior, termed here "limb rocking," pereopods $1-4$ are lifted from the substratum in various combinations, usually 2 or more of the same side, and swayed to and fro while the crayfish is otherwise stationary. Limb rocking causes the setobranchs to jiggle and stir among the gill filaments. The podobranchs, originating on the limb coxae, show a great deal of motion with movement of the limb bases.
Podobranch movement causes the SB-setae attached to or near the posterior and medial sides of podobranchs to be pushed and pulled. The median frequency of bouts of limb rocking was $0.6 / \mathrm{h}$ ( $95 \%$ confidence limits: $0.2,1.1 ; n=24)$ during the day, $1.8 / \mathrm{h}(0.8,2.7)$ at night. Median time engaged in limb rocking was $12 \mathrm{~s} /$ $\mathrm{h}(5,44)$ during the day, $60.3 \mathrm{~s} / \mathrm{h}(26,122)$ at night. Limb rocking was second only to cheliped grooming of the cephalothorax among several grooming behaviors, both in duration and in bout frequency (unpubl. data). 

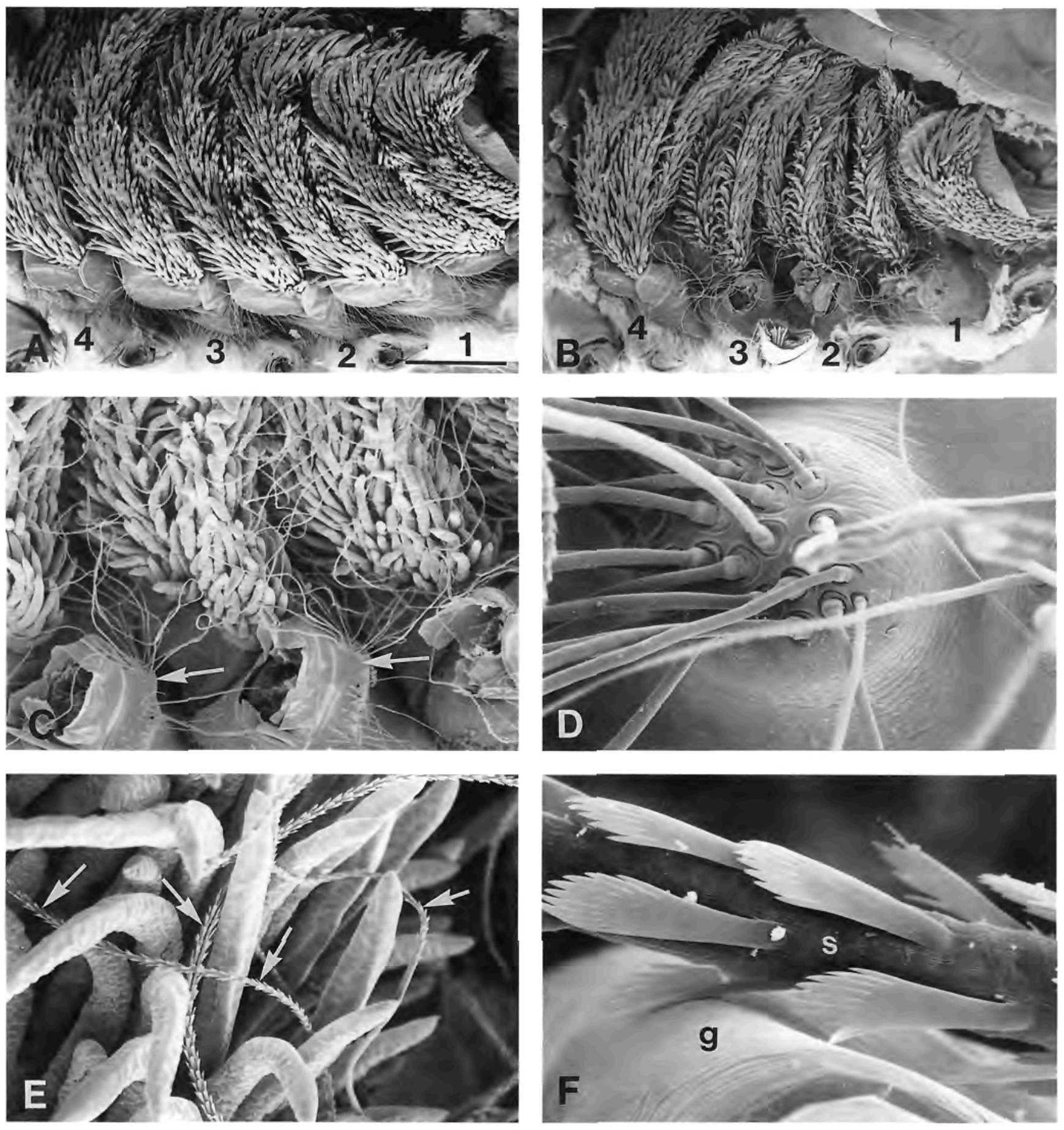

Fig. 2. A. Gill chamber of Procambarus clarkii with the branchiostegite (gill cover) removed, showing podobranch gills; $1-4$, coxae of pereopods $1-4$. Scale bar, $2 \mathrm{~mm}$. B. Same as A, with the podobranchs removed from pereopods $1-3$ and maxilliped 3 to show the anterior and posterior arthrobranchs on pereopods 1-3. Scale bar, $1.7 \mathrm{~mm}$. C. Coxae of pereopods 1-3 with podobranchs removed at their attachments (jagged openings) to reveal the setobranch papillae (arrows) on pereopods 2-3. Note setobranch setae extending from setobranchs toward the filaments of the arthrobranch gills. Scale bar, $590 \mu \mathrm{m}$. D. Anterior view of a setobranch (papilla), showing deep cuticular sockets and naked proximal portions of the setobranch setae. Scale bar, $110 \mu \mathrm{m}$. E. Setobranch setae (arrows) intertwined around gill filaments. Scale bar, $200 \mu \mathrm{m}$. F. Part of a setobranch seta (s) with digitate scale setules in position to scrape a portion of a gill filament (g). Scale bar, 9 $\mu \mathrm{m}$. 

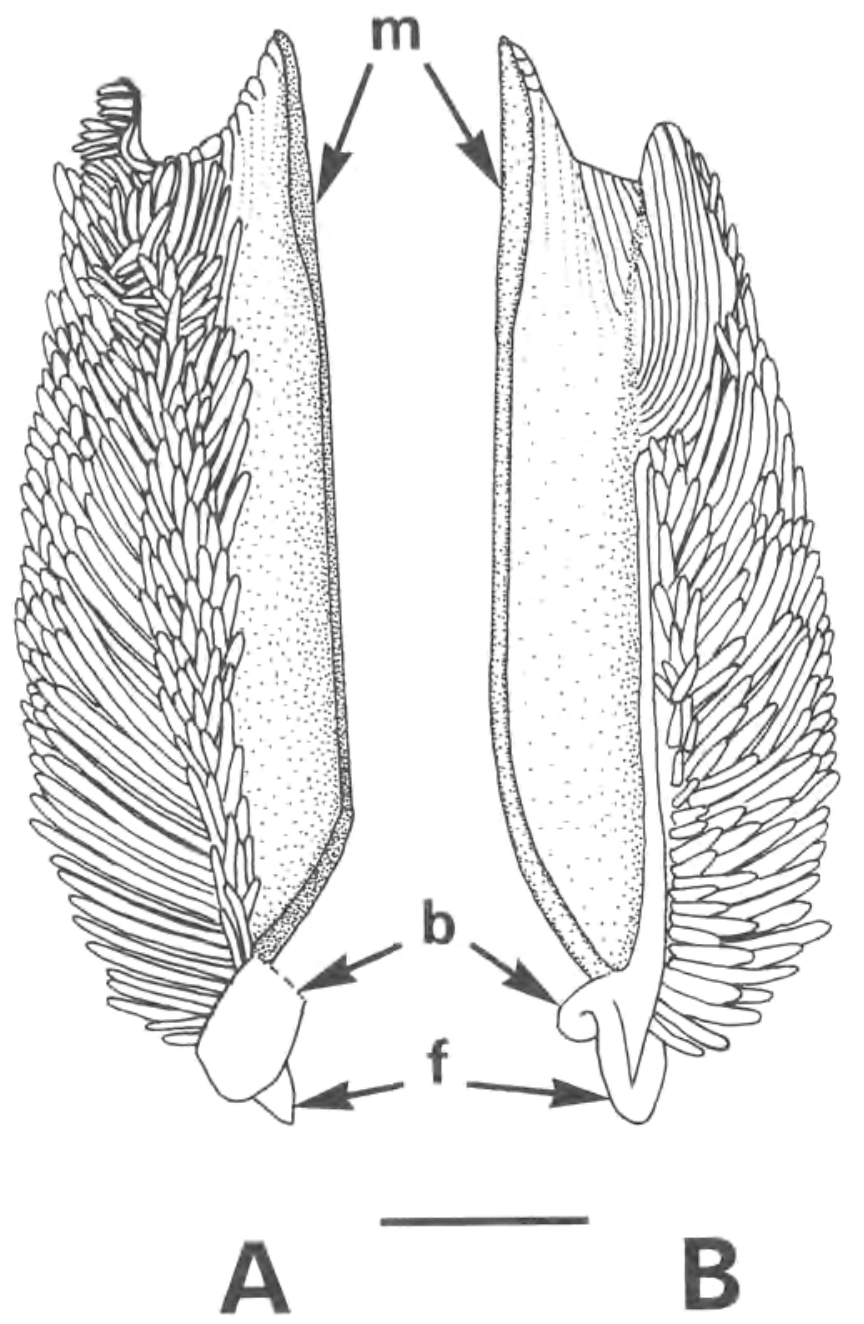

Fig. 3. Podobranch gill from branchial chamber of right side viewed from an $(\mathbf{A})$ anterior and $(\mathbf{B})$ posterior view to show the lateral (with gill filaments) and medial (m, chiefly without filaments) epipodial blades. Anterior boss (b) or shield of podobranch; epipod flange (f). Scale bar, $3 \mathrm{~mm}$.

\section{Setae on the inner side of the gill cover}

The inner side of the gill cover, or branchiostegite, is covered with setae (branchiostegal setae = "BRsetae") whose microstructure and position indicate a gill-cleaning function (Fig. 4B-E). The branchiostegite lies against lateral sides of the podobranchs. Crosssections of the branchial chamber show that the BRsetae project into and among the mass of gill filaments on the lateral side of podobranchs. With appendage movements which entail motion of limb coxae, including "limb rocking," podobranchs are jostled against the branchiostegite, causing movement of BRsetae among the gill filaments.

A BR-seta is very similar to a setobranch seta in microstructure. The base of the seta is set in a thin cuticle, giving flexibility of motion (Fig. 4D). Most of the setal shaft is covered with digitate scale setules identical to those on a setobranch seta (Fig. 4A,C,E). However, the tip of a BR-seta is equipped with a characteristic hook (Fig. 4F) rather than the simple tapered tip of a SB-seta.

\section{Experiments on gill cleaning by setobranch setae}

Description of particulate fouling. Gills from the "experimental" branchial chamber (setobranchs removed) showed a noticeably greater discoloration than those from the "control" chamber (no setobranch ablation) on the opposite side of the crayfish. The difference in discoloration was due to particulate fouling (Figs. 5-7). The pattern of fouling differed among gill types and areas of gills. In both the anterior and posterior arthrobranchs, particulate fouling was qualitatively greater on the posterior than the anterior faces of the gills (cf. Figs. 5A,B, 6A,B with Fig. 6E,F). Greater accumulations of debris were observed on the lower or proximal portions of the gill than in the upper or distal portions. In the podobranchs, debris was noticeable on the posterior side of both epipod blades (Fig. 7A,B) and on the anterior side of the medial blade (Fig. 7C). However, little particulate fouling was noticeable on or among the great mass of gill filaments of the podobranch, located on the lateral side of the lateral epipod blade (Fig. 7D). An exception was the distal end of the lateral epipod blade, where noticeable debris was observed on the experimental gills, without setobranchs, but not on the control gills, with setobranchs (Fig. 7E,F). Setobranch setae do extend out from under the podobranchs and contact the distal ends (only) of the lateral side of the podobranchs (Fig. 1A),

Particulate fouling consisted of accumulations of small sediment particles (Fig. 5E) or, more often, an amorphous flocculent substance, possibly a mixture of fine sediment and detrital particles (Fig. 5F). Often associated with the amorphous flocculent material were tangles of filamentous bacteria (Figs. 7C, 9E,F).

Measurement of particulate fouling. Gill transparency was significantly lower in experimental gills than in control gills for both the anterior and posterior arthrobranchs, in both areas of each gill type measured, for both the pond and swamp experiment (Fig. $8 \mathrm{~A}, \mathrm{~B})$. There was no overlap in $95 \%$ confidence limits for median transparency except for the upper area of the posterior arthrobranchs in the swamp experiment (Fig. 8B). For podobranchs, medians of transparency for experimental gills were lower than those of control gills, with little or no overlap in the pond experiment but considerable overlap in the swamp experiment (Fig. 8C).

The hypothesis that gill transparency for experimen- 

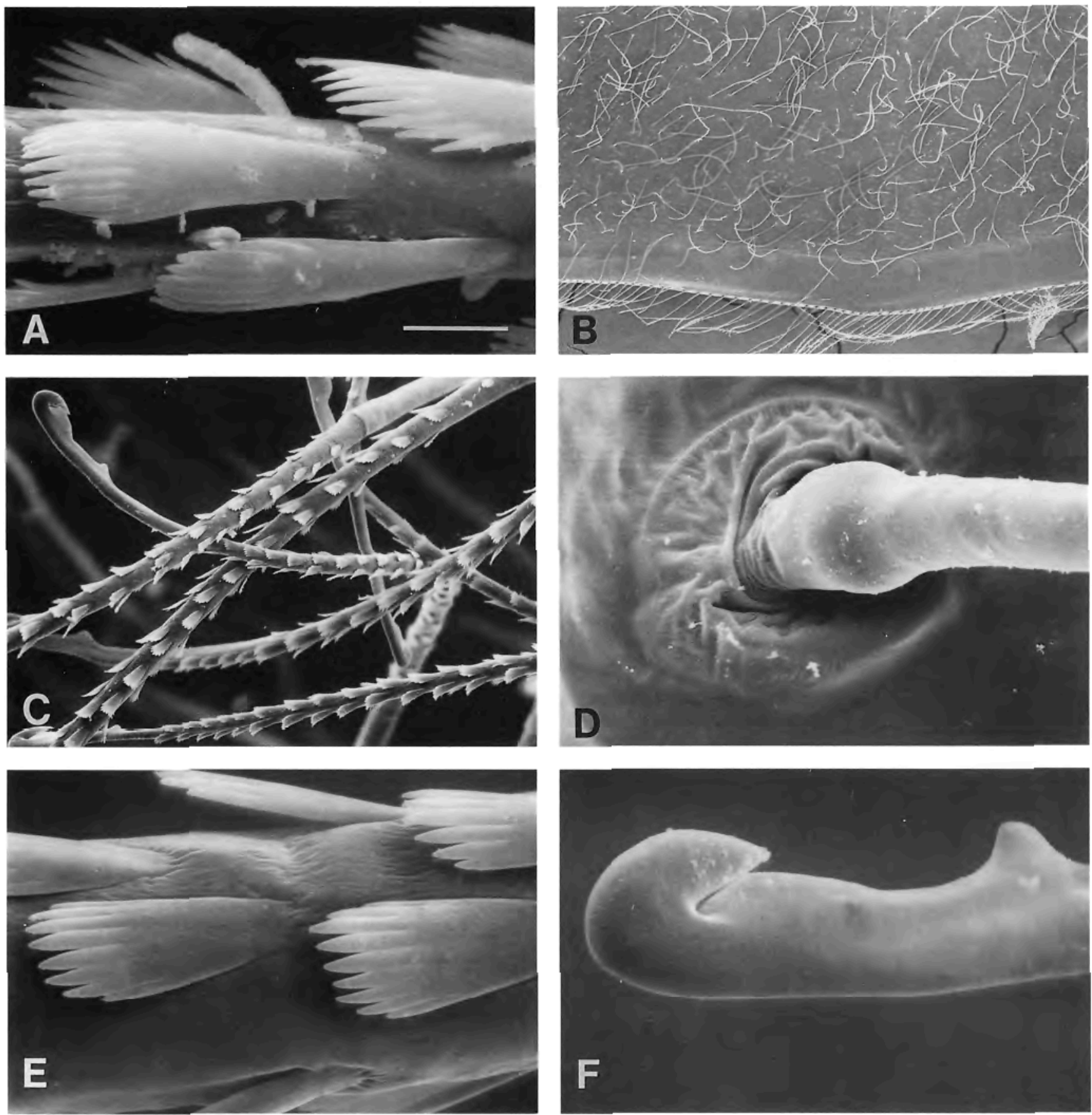

Fig. 4. A. Section of shaft of a setobranch seta showing digitate scales. Scale bar, $4 \mu \mathrm{m}$. B. Inner (medial) side of the branchiostegite, showing field of setae. Scale bar, $730 \mu \mathrm{m}$. C. Higher magnification of branchiostegal setae shown in B. Scale bar, $29 \mu \mathrm{m}$. D. Base of a branchiostegal seta set in flexible cuticle. Scale bar, $9 \mu \mathrm{m}$. E. Scale setules on the shaft of a branchiostegal seta. Scale bar, $4 \mu \mathrm{m}$. F. Hook on end of a branchiostegal seta (similar one seen at lower power, upper left of C). Scale bar, $5 \mu \mathrm{m}$.

tal gills was different from that of control gills was tested for each set of gill type, gill area, and experiment with Wilcoxon signed-ranks tests. The null hypothesis that the median of differences in transparency of control vs. experimental paired values is 0 (i.e., ex- perimental transparencies not different than controls) was rejected for all sets of comparisons $(\mathrm{p} \leq .002)$.

Epibiotic fouling. The $95 \%$ confidence limits on the median number of ciliates, C. variabilis (Fig. 9A,B), showed little overlap between experimental and 

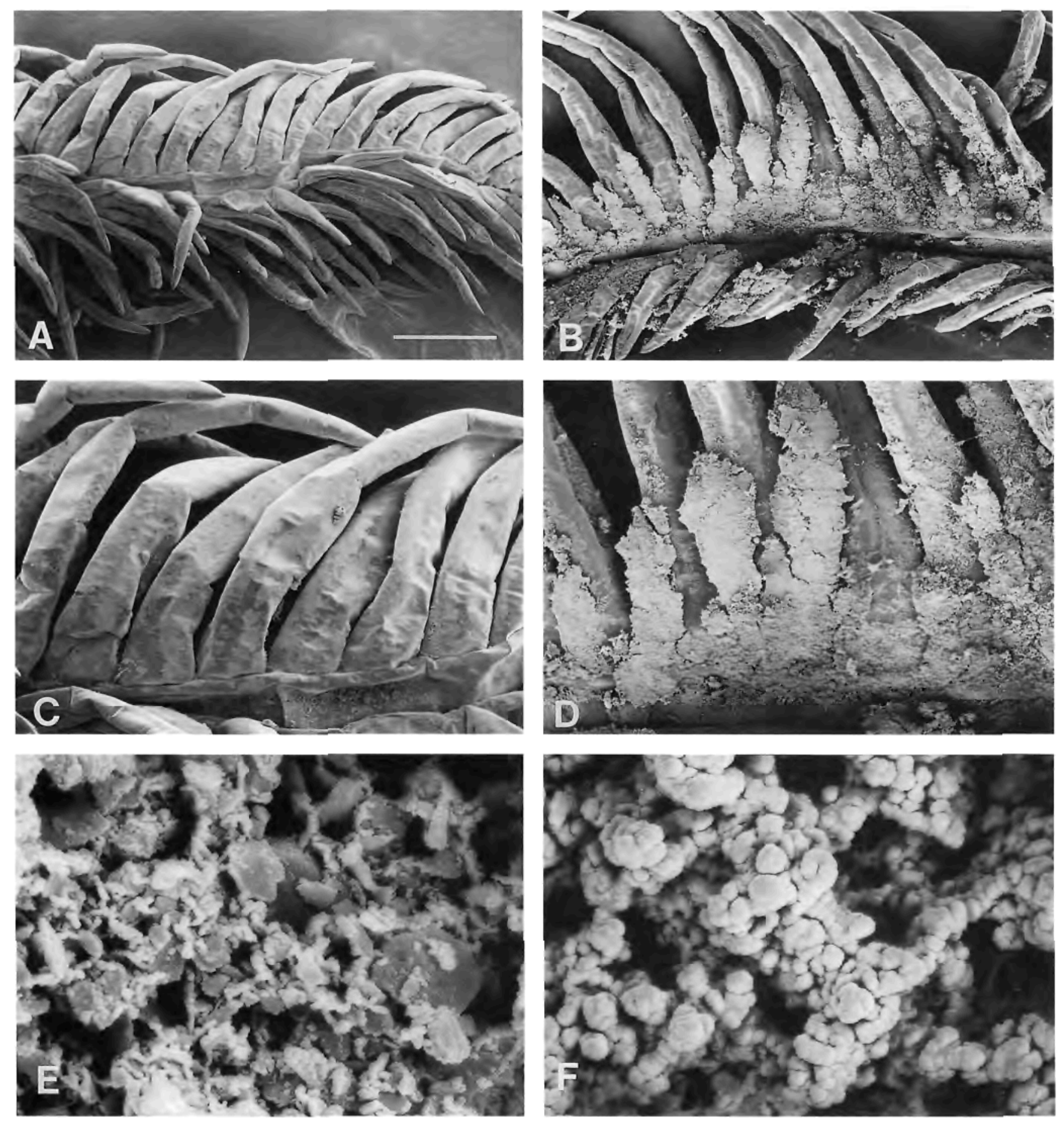

Fig. 5. Particulate fouling on posterior side of anterior arthrobranch gills, pereopod 3, from "swamp" setobranch ablation experiment. A. Gill from control gill chamber. Scale bar, $950 \mu \mathrm{m}$. B. Equivalent gill from experimental chamber; note heavy particulate fouling absent in A. Scale bar, $950 \mu \mathrm{m}$. C. Higher magnification of gill axis and filaments of control gill from A, with low particulate fouling. Note that filaments are covered with a film (lighter tone), which is bacterial growth (see Fig. 9C,D). Scale bar, $400 \mu \mathrm{m}$. D. Higher magnification of gill filaments from B, showing heavy particulate fouling. Scale bar, $400 \mu \mathrm{m}$. E, F. Particulate fouling, possibly sedimentary in E, flocculent particulates in F. Scale bar, $2 \mu \mathrm{m}$ in E, $5 \mu \mathrm{m}$ in $\mathrm{F}$. 

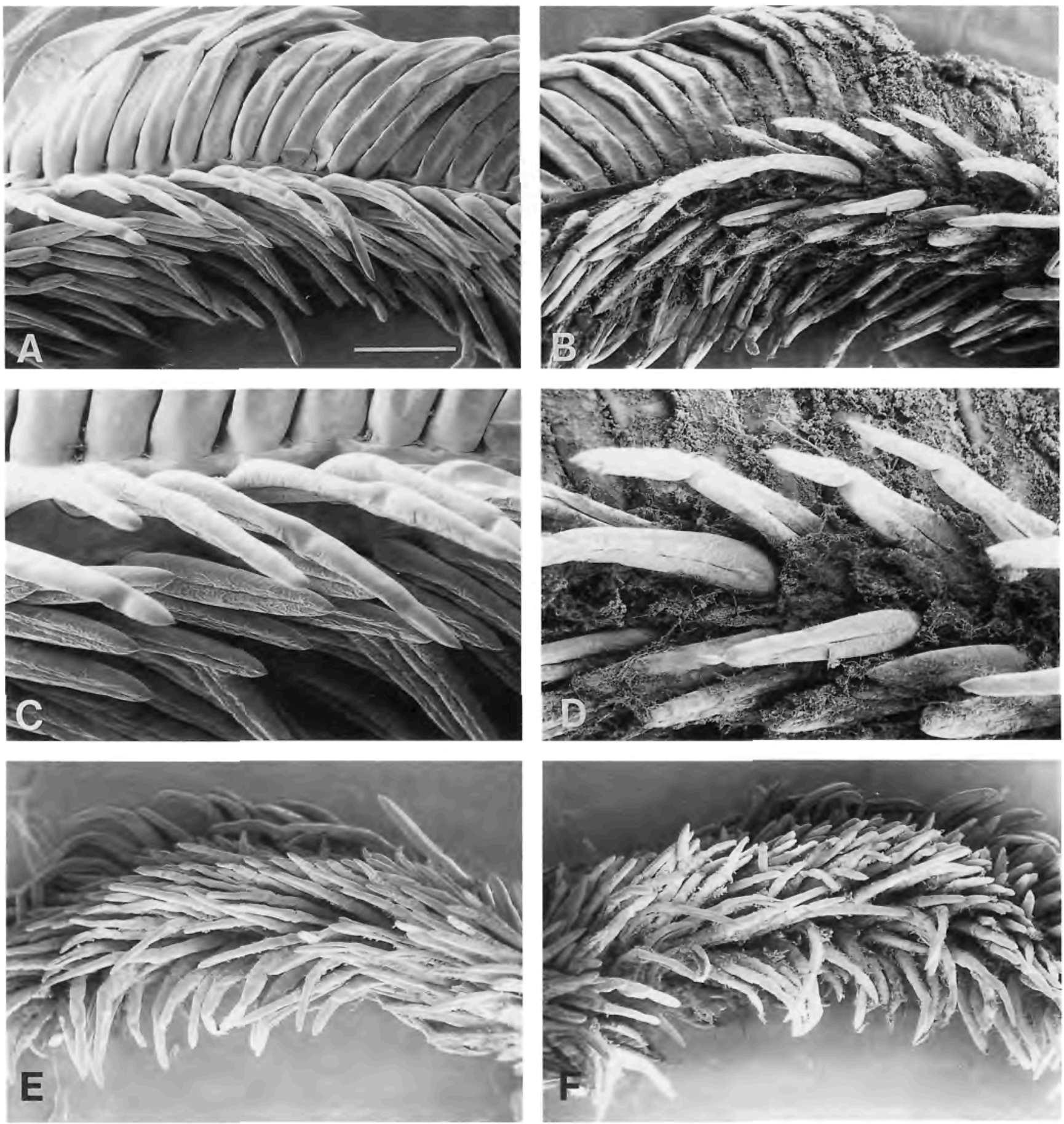

Fig. 6. A-D. Particulate fouling on posterior side of posterior arthrobranch gills, pereopod 2, from "pond" setobranch ablation experiment. A. Gill from control chamber; particulate fouling absent. Scale bar, $1 \mathrm{~mm}$. B. Equivalent gill from experimental chamber, particulate fouling between and on gill filaments. Scale bar, $1 \mathrm{~mm}$. C. Higher magnification of A, showing lack of fouling. Scale bar, $500 \mu \mathrm{m}$. D. Higher magnification of B, showing heavy fouling on and between filaments. Scale bar, $500 \mu \mathrm{m}$. E, F. Anterior side of posterior arthrobranchs, pereopods 3, swamp experiment, from control (E) and experimental $(\mathrm{F})$ gill chambers, with relatively light particulate fouling among the filaments from the experimental chamber (compare A\&E, B\&F). The small objects on filaments in E are sessile ciliates (see Fig, 9A,B). Scale bar, $1.4 \mathrm{~mm}$ in E, 1.5 $\mathrm{mm}$ in $\mathrm{F}$. 

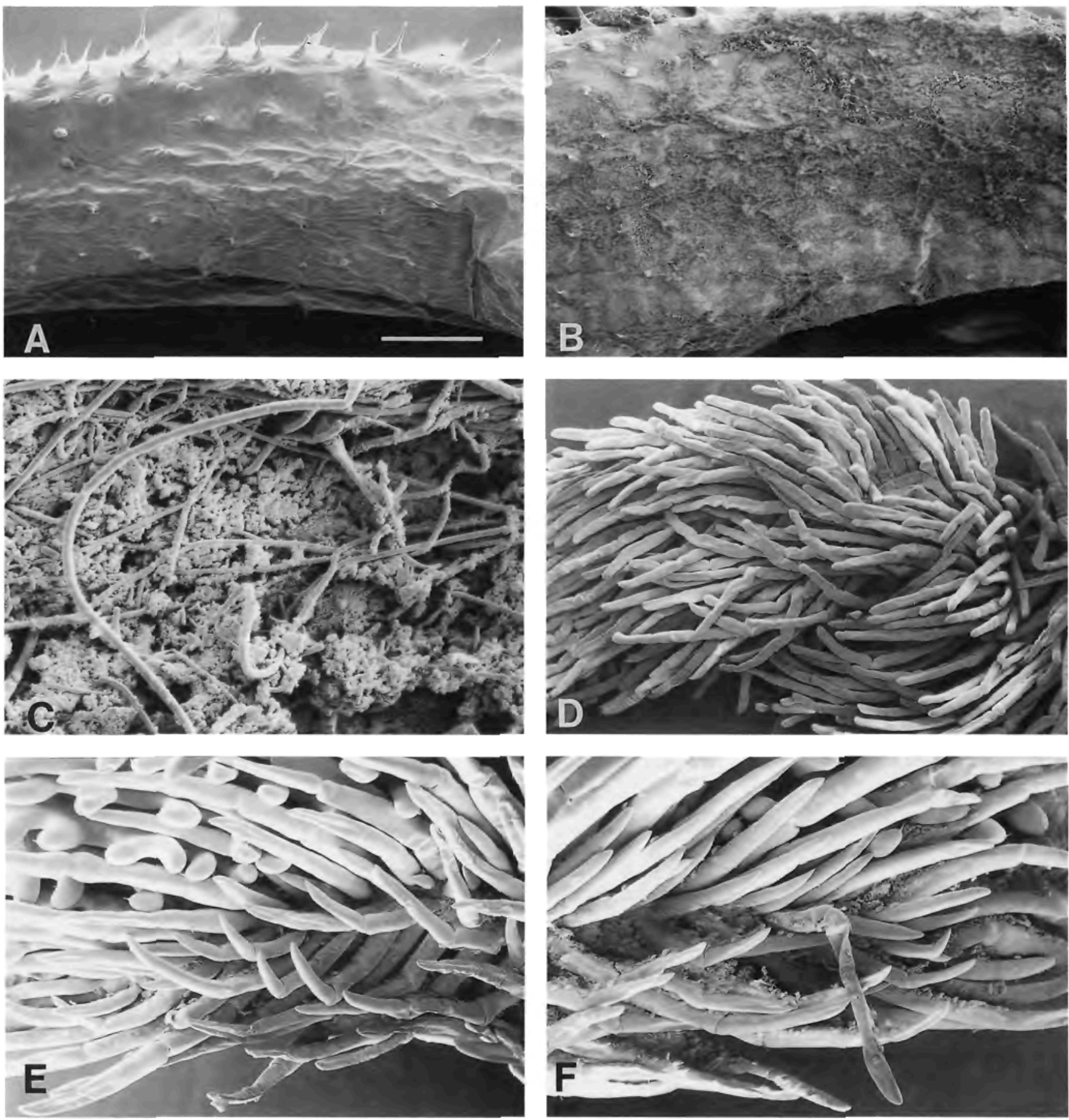

Fig. 7. Particulate fouling on podobranch gills. A, B. Anterior side of medial epipodial blade of pereopod 2 podobranch from control (A, not fouled) and experimental (B, heavy fouling) chambers. Scale bar, $400 \mu \mathrm{m}$. C. Higher magnification of fouling from B, a mixture of particulate fouling and associated filamentous bacteria. Scale bar, $22 \mu \mathrm{m}$. D. Mass of gill filaments on outer side of lateral epipodial blade of podobranch, pereopod 4, experimental; note lack of particulate fouling. Scale bar, $1.4 \mathrm{~mm}$. E, F. Comparison of particulate fouling on distal end, outer side of lateral podobranch gills, pereopod 3 , swamp experiment. Note particulate fouling in F (experimental chamber) and its relative absence in E (control chamber). Scale bar, $690 \mu \mathrm{m}$. 


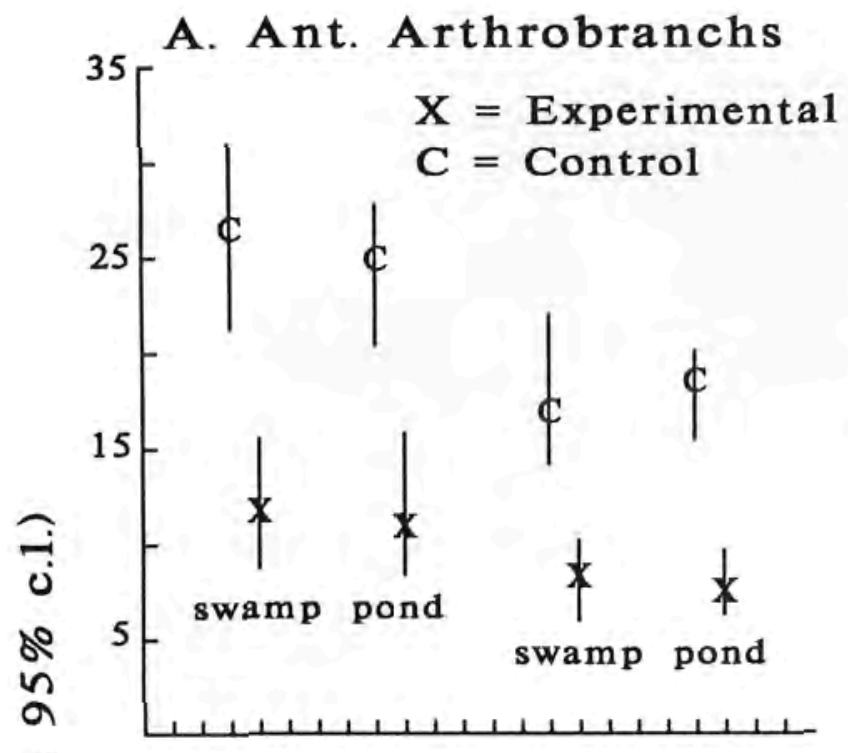

control gills in both the swamp and pond experiments (Table 1). The medians for control gills were greater than those of experimental gills, a result not expected under a hypothesis of a gill-cleaning function for the setobranchs. The null hypothesis that the median of differences in number of ciliates of control vs. experimental paired values is not different from 0 was rejected for both the pond and swamp experiments $(\mathrm{p} \leq .002)$.

Microbial fouling consisted of filamentous and rod bacteria on gill filaments (Fig. 9C-F). Although bacterial fouling was not quantified, filaments of control gills, usually free of particulate and associated filamentous fouling, often showed extensive covering by patches of bacilli, similar to that on experimental gills (Figs. 5C, 9C).

\section{Discussion}

Experiments in this study demonstrate that the setobranch (SB) setae of Procambarus clarkii have an antifouling function. Their actions keep the gill filaments free of accumulations of sediment and detrital particles carried into the branchial chamber by the respiratory stream. The jostling of SB-setae among gill filaments is caused by limb movements. Coxae of thoracic limbs carrying setobranchs pull and push the SBsetae during limb motion. Additionally, podobranch gills located on limb coxae shift during appendage movements, causing them to rub against the underlying arthrobranchs. All these motions induce agitation of SB-setae lying between the inner side of the podobranchs and the underlying arthrobranchs. Any type of limb movement involving motion of the coxae, such as feeding or locomotion, thus passively or indirectly invokes gill cleaning.

A previously unreported behavior, limb rocking, composed of back and forth movements of setobranchbearing limbs, occurs when the crayfish is otherwise at rest. Limb rocking appears to be a specific gillcleaning behavior which causes motion of limb coxae and thus of SB-setae and podobranchs. A similar behavior with possibly the same function has been in observed in caridean shrimps such as Pandalus danae STIMPSON (unpubl. data) which have setobranchs with

$\leftarrow$

Fig. 8. Comparison of particulate fouling on gills using measures of gill transparency to transmitted light. Medians and $95 \%$ confidence limits of relative transparency are given for the upper and lower parts of a single gill (pereopod 2 or 3 ) from the control (setobranch setae present) and from the experimental (setobranch setae ablated) gill chamber of 20 individuals for both the swamp and pond experiments. 

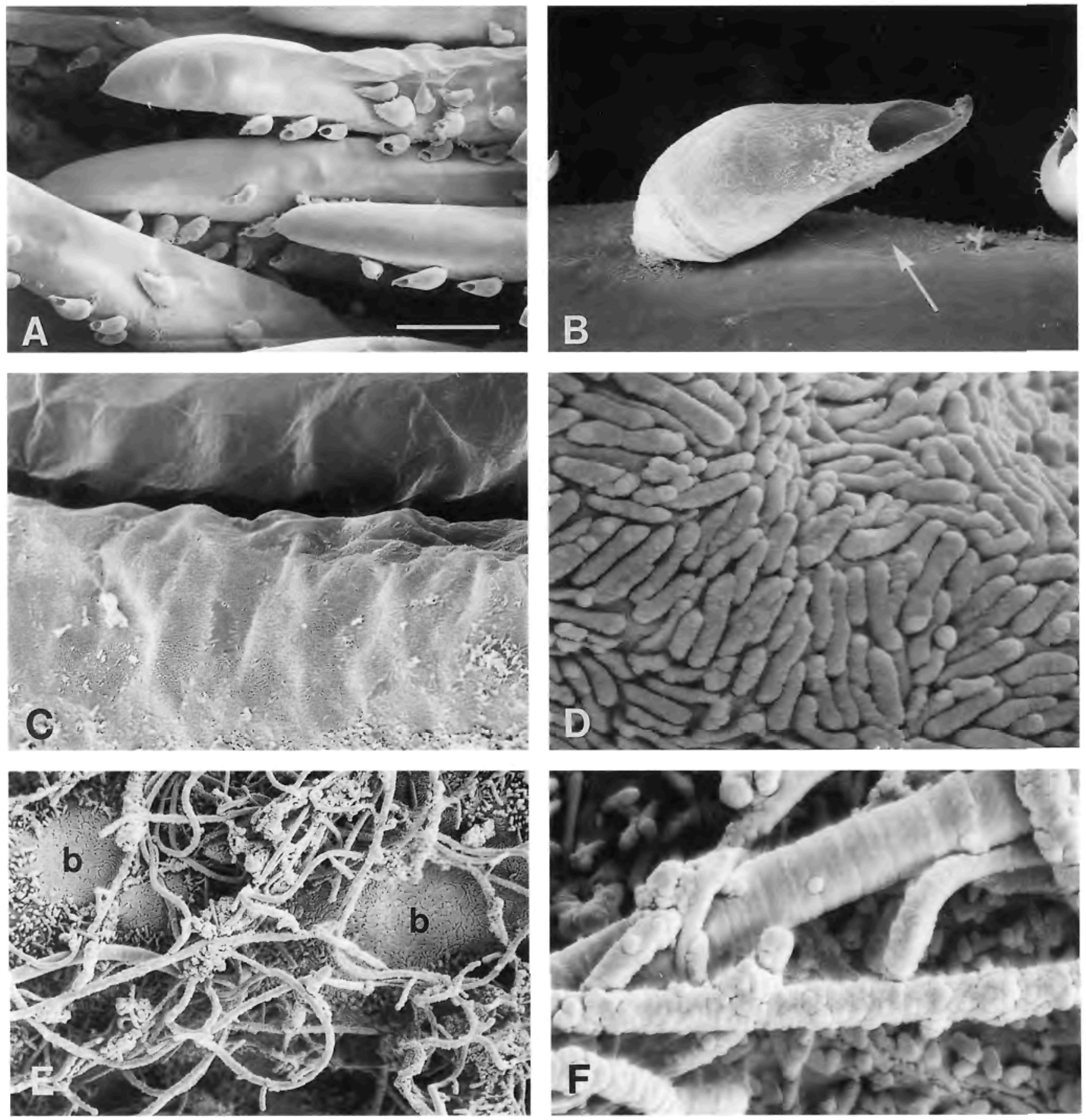

Fig. 9. Epibiotic fouling on gill filaments. A. Numerous loricae of ciliate Cothurnia variabilis on filaments of an anterior arthrobranch from a control gill chamber. Scale bar, $140 \mu \mathrm{m}$. B. Lorica of $C$. variabilis on a gill filament; also note the bacterial patch (arrow) on the filament surface. Scale bar, $22 \mu \mathrm{m}$. C. Portions of two gill filaments from an anterior arthrobranch from a control chamber; note clean filament (above) and the filament (below) covered with bacterial cells. Scale bar, $20 \mu \mathrm{m}$. D. Higher magnification of bacteria shown in B,C, and patches in E. Scale bar, $2 \mu \mathrm{m}$. E. Filamentous bacteria on a gill filament from a posterior arthrobranch, experimental chamber; note patches of bacilli (b) also on the filament. Scale bar, $19 \mu \mathrm{m}$. F. Higher magnification of the filamentous bacteria from E. Scale bar, $4 \mu \mathrm{m}$. 
Table 1. Fouling on filaments of anterior arthrobranchs by an epibiont, the peritrichous ciliate Cothurnia variabilis. Median and 95\% confidence limits (in parentheses) are given for counts of the ciliate on a standard section of an anterior arthrobranch gill for the control (setobranch setae present) and experimental (SB-setae absent) branchial chambers of treated crayfishes in the pond and swamp experiments $(\mathrm{n}=$ 20 in each)

\begin{tabular}{lcc}
\hline \hline Habitat & Control & Experimental \\
\hline Pond & $86(56,187)$ & $54(31,77)$ \\
Swamp & $64(46,158)$ & $40(16,51)$ \\
\hline
\end{tabular}

multiscaled setae similar to those of $P$. clarkii (Bauer 1979). In rocking behavior, a shrimp at rest sways its body, anchored on setobranch-bearing pereopods, from side to side. These swaying movements bring about motion of the setobranch setae among the gills, similar to limb rocking in $P$. clarkii. These observations suggest the hypothesis that limb rocking or some equivalent will be found in carideans with setobranchs and absent in species which lack them.

In $P$. clarkii, SB-setae are studded with large digitate scale setules, an apparent adaptation for scraping over gill filaments and for dislodging sediment particles. Setae of similar microstructure are found in thick tufts on chelae of caridean shrimp species which actively brush and clean the gills (Bauer 1979), implying a similar function. Setobranchs with multidenticulate setae are characteristic of caridean shrimps in which cheliped brushing has not been observed (Bauer 1979). Experiments have never been done to test the hypothesis of a gill-cleaning function for setobranchs in a caridean shrimp (Bauer 1979, 1989). However, the experiments on crayfish setobranchs in this study strongly suggest that the setobranchs of caridean shrimps prevent particulate fouling on gills.

One major component of the gill complex of $P$. clarkii, the mass of filaments on the outer side of the podobranchs, is out of reach of the SB-setae. These gill filaments are apparently kept free of sediment by the branchiostegal (BR) setae which project out from the inner side of the branchiostegite. In the setobranch ablation experiments, there was no discernible buildup of particulate fouling on the podobranch filaments in contact with BR-setae, either in the experimental or control chambers. The terminal hook at the tip of the BR-seta may serve to catch onto gill filaments and keep the rather short BR-setae in place and in contact with the filaments.

As effective as SB- and BR-setae may be in thwarting particulate fouling, they do not keep gill filaments free of epibiotic fouling. Ciliate fouling, especially by the sessile peritrich Cothurnia variabilis, was common and quite severe in some crayfishes exposed to fouling in both the pond and swamp habitats. Paradoxically, numbers of ciliates were significantly greater on control gills (with SB-setae) than experimental gills (without SB-setae). Heavy particulate fouling on the experimental gills may have hidden some of the ciliates from view. Also, particulate fouling may have created poor habitat for the ciliate. In any case, the presence of SB-setae did not lower nor prevent ciliate fouling on control gills. Microbial fouling appeared similar between experimental and control gills, with dense colonies of bacilli occurring in extensive patches over large areas of filaments. However, filamentous bacteria were especially abundant on areas of heavy particulate fouling, i.e., on experimental gills. It is hypothesized that the filamentous bacteria were associated with increased substrate due to particulate fouling rather than with an absence of cleaning by SB-setae.

Results of this study have shown a lack of defenses in P. clarkii against epibiotic fouling on the gills. This is supported by observations of Scott \& Thune (1986) on gill ectocommensals of this species in commercial crayfish ponds. They reported a correlation between incidence of gill ectocommensals and nutrient concentrations that promote growth of bacteria, some of which foul gills and others of which serve as food for ectocommensal protozoans. No obvious detrimental effects of ciliate fouling were reported by Scott \& Thune (1986) nor were obvious in this study on treated crayfishes, which also suffered severe particulate fouling in one of the two branchial chambers. However, the experiments in this study were carried out during the winter months when ambient oxygen is presumably high. Scott \& Thune (1986) and Vogelbein \& Thune (1988) have pointed out that effects of heavy epibiotic fouling might have adverse effects on crayfishes during periodic occurrences of poor water quality in commercial ponds. Such conditions, specifically low oxygen concentration, may take place not only in commercial ponds but also in the temporary bodies of water in which $P$. clarkii normally occurs in nature.

Relief from epibiotic fouling of the gills comes to $P$. clarkii only from molting, which casts off all fouling organisms. However, significant buildup of epibiotic fouling by ciliates and bacteria can occur rapidly between molts in crustaceans. Heavy bacterial fouling occurred within 1-2 weeks on the gills of marine shrimps (Bauer 1979) and stomatopods (Bauer 1986) deprived of gill-cleaning appendages. Similarly, significant ciliate fouling occurred on various body parts within two weeks in shrimps deprived of grooming chelipeds. Treated crayfishes in this study did not molt during the pond ( 2 weeks) nor swamp (7 weeks) ex- 
periment, although molting may have been inhibited by food deprivation and caging. However, intermolt periods of 3-5 weeks are typical for similarly-sized subadult and adult crayfishes in laboratory studies at temperatures of $22-23^{\circ}$ (Nakatani \& Otsu 1979; R.T. Bauer, unpubl. data). Consequently, $P$. clarkii is certainly susceptible to epibiotic fouling, both ciliate and bacterial, in commercial pond and natural habitats.

The lack of defense against epibiotic fouling in $P$. clarkii is significant also in light of the increasing invasion of south Louisiana waterways by the zebra mussel, Dreissena polymorpha (PALLAS) (Mackie \& Schloesser 1996). Zebra mussels now are recruited and grow in the Atchafalaya Basin (T. Mihuc, pers. comm.; R.T. Bauer, unpubl. data), a natural habitat and site of the major commercial fishery of $P$. clarkii. This fouling organism can settle and grow on the exoskeletons of crayfishes (Carlton 1993; Nalepa \& Schloesser 1993: plate 12: J. Brazner \& D. Jensen, pers. comm. on Orconectes rusticus). If larvae of D. polymorpha become abundant and enter the branchial chamber of $P$. clarkii, there is no host defense to prevent settlement. Attachment and growth of settling stages of this exotic fouler on the gills would certainly be harmful to crayfishes.

The effectiveness of setobranch setae against particulate but not epibiotic fouling supports the view (Bauer 1981, 1989) that indirect gill-cleaning methods are primitive and that cheliped brushing of gills is a derived character in the Decapoda. In the caridean shrimp family Hippolytidae, some species have a full set of setobranchs and no gill brushing, some have a reduced set with gill brushing, and still others have no setobranchs but brush the gills (Bauer 1984). Reduction in a serially homologous structure (setobranchs) was invoked to hypothesize that setobranchs had been replaced by cheliped brushing as a gill-cleaning mechanism in various hippolytid and other caridean shrimp taxa (Bauer 1984). It was suggested that gill brushing, in which the shrimp can actively brush and pick specific items from its gills, was more efficient than the passive setobranch method, and thus is selected for when genetic variation allows (Bauer 1984). Experiments in this study show that setobranchs are indeed ineffective against epibiotic fouling, while experiments in caridean shrimps showed that epibiotic fouling was prevented by gill brushing. Therefore, the view that gill brushing is more advanced, both in the functional and evolutionary sense, than setobranchs and other indirect methods, is supported. It is likely that the "UrDecapod" had an indirect method, either setobranchs or setiferous epipods, for gill cleaning. Gill brushing has evolved in stenopodidean shrimps, in several caridean shrimp taxa, and in anomurans with concurrent loss of indirect gill-cleaning mechanisms. However, indirect gill cleaning has been retained in many decapod taxa, including phylogenetically advanced groups such as brachyuran crabs.

Acknowledgments. This work was made possible by funding from the NOAA Louisiana Sea Grant Program (Grant \# NA46RG0096-R/ZM-4). My sincere thanks to: Marilyn Barrett-O'Leary, coordinator of the Zebra Mussel Program, for administrative support and exchange of information; Russell Huval, crayfish pond owner, for supply of crayfishes and use of ponds for cage experiments; and Dr. Tim Mihuc, Louisiana State University, for invaluable and unselfish support of field experiments in the Atchafalaya Basin. Thanks are due to Dr. John Clamp, North Carolina State University, for information on Cothurnia variabilis, and to Drs. Kevin Carman and John Larkin, Louisiana State University, for looking over the bacterial fouling on gills. This paper is dedicated to the late Dr. Horton H. Hobbs, Jr., a true gentleman and scholar, whose contributions to crayfish and crustacean biology have been an inspiration. This is Contribution No. 59 of the Laboratory of Crustacean Research.

\section{References}

Bauer RT 1979. Antifouling adaptations of marine shrimp (Decapoda: Caridea): gill cleaning mechanisms and cleaning of brooded embryos. Zool. J. Linn. Soc. 65: 281-303. 1981. Grooming behavior and morphology in the decapod Crustacea. J. Crustacean Biol. 1: 153-173.

- 1984. Morphological trends in the genus Heptacarpus (Decapoda, Caridea) and their phylogenetic significance. J. Crustacean Biol. 4: 201-225.

1986. Stomatopod grooming behavior: functional morphology and amputation experiments in Gonodactylus oerstedii. J. Crustacean Biol. 7: 414-432.

1989. Decapod crustacean grooming: functional morphology, adaptive value, and phylogenetic significance. In: Functional Morphology of Feeding and Grooming in Crustacea. Felgenhauer BE, Watling L, \& Thistle AB, eds., pp. 49-73. A.A. Balkema, Rotterdam.

Carlton JT 1993. Dispersal mechanisms of the zebra mussel (Dreissena polymorpha). In: Zebra Mussels. Nalepa TF \& Schloesser DW, eds., pp. 677-698. Lewis Publ., Boca Raton.

Hobbs HH Jr 1974. A checklist of the North and Middle American crayfishes (Decapoda: Astacidae and Cambaridae). Smith. Contr. Zool. 166, $161 \mathrm{pp.}$

Huxley TH 1880. The Crayfish. C. Kegan Paul \& Co., London. 371 pp.

Mackie GL \& Schloesser DW 1996. Comparative biology of zebra mussels in Europe and North America: an overview. Am. Zool. 36: 244-258.

Nakatani 1 \& Otsu T 1979. The effects of eyestalk, leg, and uropod removal on the molting and growth of young crayfish. Procambarus clarkii. Biol. Bull. 157: 182-188.

Nalepa TF \& Schloesser DW, eds. 1993. Zebra Mussels. Lewis Publ., Boca Raton. 810 pp.

Penn GH 1959. An illustrated key to the crawfishes of Lou- 
isiana with a summary of their distribution within the state (Decapoda, Astacidae). Tulane Stud. Zool. 7: 3-20.

Pohle G 1989. Gill and embryo grooming in lithodid crabs: comparative functional morphology based on Lithodes maja. In: Functional Morphology of Feeding and Grooming in Crustacea. Felgenhauer BE, Watling L, \& Thistle AB, eds., pp. 75-94. A.A. Balkema, Rotterdam.
Scott JR \& Thune RL 1986. Ectocommensal protozoan infestations of gills of red swamp crawfish, Procambarus clarkii (Girard), from commercial ponds. Aquaculture 55: 161-164. Vogelbein WK \& Thune RL 1988. Ultrastructural features of three ectocommensal protozoa attached to the gills of the red swamp crawfish, Procambarus clarkii (Crustacea: Decapoda). J. Protozool. 35: 341-348. 